\title{
Subject-defined vs. experimenter-defined conflict
}

\author{
EUGENE L. RINGUETTE and THOMAS R. SCHILL \\ Southern Ilinois University, Carbondale, Illinois 62901
}

\begin{abstract}
This study tested whether situations defined as conflictual by the subject evoke more intense conflict, as measured by response time, than do situations defined as conflictual by the experimenter. The subjects were 22 undergraduate students, and paired adjectives were used as conflict trials. The results indicated that subject-defined conflicts are experienced as more intense than experimenter-defined conflict, and it is submitted that this can be interpreted most meaningfully within an interactional framework.
\end{abstract}

A recent study by Ringuette (1976) indicates that there is a notable degree of stability of individual differences in response to different types of conflict and suggests that this finding may be most meaningfully considered within an interactionist framework such as that proposed by Bowers (1973). The present study is concerned with the possibility that different individuals perceive conflict in different ways and that the individual's subjective definition of a conflict will evoke more intense conflict behavior than will a conflict defined in purely situational terms.

Most of the previous work on conflict behavior, including that done with humans, has utilized conflict situations defined as conflictual by the experimenter (e.g., Arkoff, 1957; Hovland \& Sears, 1938; Worell, 1962). One exception to this is a study reported by Schill (1966) in which conflicts were devised based on the subjects' own ratings of adjectives. In light of Ringuette's (1976) findings, it is reasonable to assume that individuals define conflict in certain individualistic ways, as well as common ways, and that their responses to such self-defined conflicts will differ from their responses to other-defined conflicts. The primary hypothesis of the present study was that subjects would experience greater conflict, as evidenced by longer response times, in subject-defined conflict situations.

\section{METHOD}

The subjects were 22 introductory psychology students. The conflict trials were presented in the same manner as described in Ringuette (1976). Briefly, the subject was seated at a console in which there were two windows, with a button corresponding to each window. On each trial, a pair of words, one in each window, was presented simultaneously to the subject. His response to the trial was to press the button corresponding to the window which contained the word of his choice. The appearance of the words in the window activated a timer which was deactivated by the buttonpress. Thus, the response measure was response latency, which included both decision time and reaction time.

The instructions were phrased so as to emphasize the avoidance aspect of the choice by asking the subject to choose the least desirable if one of the words was to be applied to him. This was done in order to maximize conflict (Murray, 1976; Ringuette, 1965) and to make the conditions as comparable as possible in that respect. Each subject was presented with four conflict conditions of three trials each, in addition to three practice trials. The four conflict conditions were: (1) Low conflict-a pair of words of which one was clearly desirable and one was clearly undesirable (e.g., health-sickness). (2) Subjectdefined (Arkoff) conflict-the presentation of a pair of adjectives taken from the list used by Arkoff (1957). Unlike Arkoff's original procedure, however, the words were paired according to the similarity ascribed to the words by the subject's prior ranking. (3) Experimenter-defined (Arkoff) conflict-the presentation of pairs of adjectives selected in the same manner as in Arkoff's (1957) study, that is, adjectives paired in such a way as to induce conflict according to Arkoff's judgment regarding the emotional value of the adjectives. (4) Subject-defined (Schill) conflict-adjectives which had been previously rated on an approval-disapproval scale by each subject were paired according to the equivalence ascribed to them by the subject.

In summary, each subject responded to three practice trials and 12 conflict trials. The conflict trials included three trials each of low conflict, subject-defined (Arkoff) conflict, experimenter-defined (Arkoff) conflict, and subject-defined (Schill) conflict. The conflict conditions were presented in counterbalanced order. Following this presentation, the entire schedule of trials, including practice trials, was presented a second time.

\section{RESULTS}

Table 1 presents the means and standard deviations obtained for the four conflict situations on the test and retest presentations. Analysis of variance indicated statistically significant effects due to conflict situations $[F(3,63)=19.37, p<.001]$, test-retest presentations $[\mathrm{F}(1,21)=21.31, \mathrm{p}<.001]$, and the interaction of the two variables $[F(3,63)=4.36, p<.01]$.

Application of the Newman-Keuls procedure to the original test presentation indicated that the primary

Table 1

Means and Standard Deviations of Response Times to the Conflict Situations

\begin{tabular}{|c|c|c|c|c|c|c|c|c|}
\hline & \multicolumn{2}{|c|}{$\begin{array}{c}\text { Low } \\
\text { Conflict }\end{array}$} & \multicolumn{2}{|c|}{$\begin{array}{l}\text { S-Defined } \\
\text { (Arkoff) }\end{array}$} & \multicolumn{2}{|c|}{$\begin{array}{c}\text { E-Defined } \\
\text { (Arkoff) }\end{array}$} & \multicolumn{2}{|c|}{$\begin{array}{l}\text { S-Defined } \\
\text { (Schill) }\end{array}$} \\
\hline & $\overline{\mathrm{X}}$ & SD & $\overline{\mathrm{X}}$ & SD & $\overline{\mathrm{X}}$ & SD & $\overline{\mathbf{X}}$ & SD \\
\hline Presentatio & $\begin{array}{l}1.04 \\
1.01\end{array}$ & $\begin{array}{l}.47 \\
.72\end{array}$ & $\begin{array}{l}2.31 \\
1.29\end{array}$ & $\begin{array}{r}1.10 \\
.45\end{array}$ & $\begin{array}{l}1.68 \\
1.38\end{array}$ & $\begin{array}{r}.69 \\
1.28\end{array}$ & $\begin{array}{l}2.32 \\
1.57\end{array}$ & $\begin{array}{r}1.31 \\
.81\end{array}$ \\
\hline
\end{tabular}


hypothesis was confirmed by the statistically significant difference obtained between the subject-defined (Arkoff) and the experimenter-defined (Arkoff) conditions. (A criterion of $p<.05$ was used for the NewmanKeuls tests.) The subject-defined (Schill) condition also differed significantly from the experimenter-defined (Arkoff) condition. Significant differences were found, on the test presentation, between the low-conflict and each of the three high-conflict conditions, with the largest difference for the subject-defined (Schill) condition. On the retest presentation, there were no significant differences among the means of the four conflict conditions (accounting for the Conflict Condition by Test-Retest interaction).

\section{DISCUSSION}

The results strongly support the hypothesis that subjects experience greater conflict in situations in which the components are paired according to strengths assigned by the subjects, as compared to situations in which the components are paired according to strengths ascribed to them by the experimenter. More simply, one person's conflict is not necessarily another person's conflict. When the conflict situations were presented a second time, none maintained a significant difference from low conflict. This clearly suggests that subjects adapted quickly to the conflict situations, and that familiarity with the conflict situations results in less indecisiveness.

The greater conflict exhibited in experimenter-defined conflict situations, as compared to low-conflict situations, reflects the effects of the situational component of conflict on the responses of all subjects, but the greater reaction to subjectdefined conflict indicates that a meaningful study of conflict behavior must take into account the individual's perception of the situation. For the results of research on conflict behavior to contribute to personality theory in a truly meaningful way, it seems necessary that the study of conflict include the experiencing person. Without this, it is unlikely that the study of "conflict situations" will extend very far toward an understanding of the more complex experiences which are associated with human conflict behavior.

\section{REFERENCES}

ArkofF, A. Resolution of approach-approach and avoidanceavoidance conflicts. Journal of Abnormal and Social Psychology, 1957, 55, 402-404.

Bowers, K. S. Situationism in psychology: An analysis and a critique. Psychological Review, 1973, 80, 307-336.

Hovland, C. I., \& Sears. R. R. Experiments on motor conflict. I. Types of conflict and their modes of resolution. Journal of Experimental Psychology, 1938, 23, 477-503.

MurRay, E. J. Resolution of complex decisional conflicts as a function of degree of avoidance. Journal of Research in Personality, 1976, in press.

Ringuette, E. L. Mode of conflict resolution: A replication and extension. American Psychologist, 1965, 20, 548.

Ringuetre, E. L. The stability of individual differences in behavior across experimental conflict situations. Journal of Research in Personality, 1976, 10, 177-182.

Schill, T. R. The effects of type and strength of induced conflict on conflict generalization and later preference for conflict stimuli. Journal of Personality, 1966, 34, 35-54.

Worell, L. Conflict experience and conflict to tolerance. American Psychologist, 1962. 17, 300-301.

(Received for publication October 6, 1976.) 